\title{
Highlights on photocathodes based on thin films prepared by pulsed laser deposition
}

\author{
A. Lorusso, ${ }^{1, *}$ F. Gontad, ${ }^{1}$ A. Perrone, ${ }^{1}$ and N. Stankova ${ }^{2}$ \\ ${ }^{1}$ National Institute of Nuclear Physics and Physics Department, University of Salento, Via Arnesano, 73100 Lecce, Italy \\ ${ }^{2}$ Institute of Electronics, Bulgarian Academy of Sciences, 1784 Sofia, Bulgaria
}

(Received 13 May 2011; published 15 September 2011)

\begin{abstract}
We review the current status of metallic photocathodes based on thin films prepared by pulsed laser deposition (PLD) and we explore ways to improve the performance of these devices. PLD seems to be a very efficient and suitable technique for producing adherent and uniform thin films. Time-resolved mass spectrometric investigations definitively suggest that the deposition of high-purity metallic thin films should be carried out in ultrahigh vacuum systems and after a deep and careful laser cleaning of the target surface. Moreover, the laser cleaning of the target surface is highly recommended not only to remove the first contaminated layers but also to improve the quality of the vacuum by reducing the partial pressure of reactive chemical species as $\mathrm{H}_{2} \mathrm{O}, \mathrm{H}_{2}$, and $\mathrm{O}_{2}$ molecules. The challenge to realize high-purity $\mathrm{Mg}$ and $\mathrm{Y}$ thin films is very interesting for the photocathode R\&D due to the good photoemission properties of these metals. Photocathodes based on $\mathrm{Mg}$ and $\mathrm{Y}$ thin films have been characterized by scanning electron microscopy and x-ray diffraction techniques to derive the morphological and structural features, respectively. They were also tested in a photodiode cell to deduce the photoelectron properties. The quantum efficiency of such photocathodes was systematically improved by in situ laser cleaning treatments of the surface in order to remove the contaminated layers reaching, in this way, the quantum efficiency of the corresponding bulk materials.
\end{abstract}

DOI: 10.1103/PhysRevSTAB.14.090401

PACS numbers: 81.15.Fg, 52.38.Mf, 85.60.Ha

\section{INTRODUCTION}

High brightness electron beam sources play a fundamental role in high-gain free-electron lasers (FEL) development as well as for linear colliders designed to study the electron-positron collisions [1,2]. For example, the SPARC project of INFN for generating $500 \mathrm{~nm}$ of wavelength has required laser-driven rf photocathode guns capable of producing $1 \mathrm{nC}$ bunches of a few picosecond duration with about $1 \mathrm{~mm}$-mrad of emittance [3,4]. Nevertheless, the challenge to obtain future $\mathrm{x}$-ray FELs requires further improvements of the quality of the electron beams. Many laboratories are interested in $\mathrm{R} \& \mathrm{D}$ on photocathodes to find new materials capable of producing bright electron beams for the next FEL sources [5-10]. A good cathode is characterized by high robustness, promptness of emission, high quantum efficiency (QE), and low thermal emittance.

Semiconductor photocathodes, in particular the negative-affinity ones, have very high $\mathrm{QE}$, as high as 0.6 electrons per photon but long response times ( $>10 \mathrm{ps})$ [11]. Moreover, they are highly reactive and thus sensitive to the vacuum-environment quality.

\footnotetext{
*Corresponding author. antonella.lorusso@le.infn.it
}

Published by the American Physical Society under the terms of the Creative Commons Attribution 3.0 License. Further distribution of this work must maintain attribution to the author(s) and the published article's title, journal citation, and DOI.
Metallic photocathodes can be preferred because they are more robust and easier to handle. They are characterized by a prompt emission $(<1 \mathrm{ps})$ even if their QE is extremely low $\left(10^{-3}-10^{-5}\right)$. The poor QE of metals is mainly due to the high reflectivity, to the high work function as well as to the big cross section of the electronelectron scattering in the conduction band [12].

The metal QE equation derives from the well-known three-step-Spicer-photoemission model [13]:

$$
\mathrm{QE}=C\left(h v-\Phi_{0}+a \sqrt{\beta E}\right)^{2},
$$

where $C$ is a constant which depends on the material, $E$ is the extraction electric field which is responsible of the Schottky effect, $h v$ is the photon energy, $\Phi_{0}$ is the work function of material, $\beta$ is the field enhancement factor, and $a=\sqrt{\frac{e}{4 \pi \varepsilon_{0}}}\left(e\right.$ is the electron charge, $\varepsilon_{0}$ is the vacuum dielectric constant).

The thermal emittance $\varepsilon_{\mathrm{th}}$ for a photocathode derives from the same model with the following equation:

$$
\varepsilon_{\mathrm{th}}=\sigma_{t} \sqrt{E_{k} / m c^{2}} \quad \text { with } E_{k}=h v-\Phi_{0}+a \sqrt{\beta E},
$$

where $E_{k}$ is the kinetic energy of photoelectrons and $\sigma_{t}$ is the rms transverse of the laser spot size which influences the electron-bunch-diameter next to the cathode surface.

The advantage of having a reduction of thermal emittance induces, in turn, the reduction of QE; it means that a cathode with high QE could not produce high brightness electron beams. 
Currently, rf photoinjector guns use copper photocathodes because they are easy to hand, reliable, and less reactive than other metallic candidates. Nevertheless, a copper photocathode is characterized by low quantum efficiency, about $10^{-4}$ at $266 \mathrm{~nm}$ of wavelength [14].

Several research groups have been investigating the potentiality of alternative photocathodes at different operational conditions with the aim to improve the photoemission performances in the rf guns. Photocathodes have been prepared by different methods, namely, pulsed laser deposition [15,16], sputtering [7], ion implantation [17], arc deposition [8], friction welding [18], evaporation [19], hot isostatic pressure [20], and bulk disks press fitted [21]. The results of these investigations indicate that magnesium $[9,21,22]$, yttrium [16,23], and lead [8,24] are very promising metallic photocathodes.

Magnesium has a moderate work function $(3.7 \mathrm{eV})$ with a respectable QE: the highest value was measured to be $2 \times 10^{-3}$ in a rf electron gun obtained by the frequency triplet Ti:sapphire laser $(266 \mathrm{~nm}-4.7 \mathrm{eV})$ [9].

Yttrium is also interesting due to its relatively low work function $(\sim 3.0 \mathrm{eV})$, which allows the use of the $2 \mathrm{nd}$ harmonic $(400 \mathrm{~nm}-3.1 \mathrm{eV})$ of Ti:sapphire drive laser instead of the 3rd harmonic [23]. This fact means a higher and more stable laser energy as well as a reduced thermal emittance of the photoelectron beam according to Eq. (2). Moreover, the opportunity to drive a metal photocathode with the visible radiation will reduce the costs of optics which are very expensive in the case of the ultraviolet radiation.

Finally, electron sources based on lead thin film should be even more interesting due to its relatively high QE $\left(1 \times 10^{-3}\right.$ at $\left.213 \mathrm{~nm}[8]\right)$ and to its higher chemical stability and, hence, to its longer lifetime. Moreover, lead has been indicated one of the best photocathodes in hybrid lead-niobium rf guns. This metal has superconducting properties with a critical temperature of $7.2 \mathrm{~K}$ [24].

This paper reviews the main achievements on the development of metallic photocathodes based on thin films of $\mathrm{Mg}$ and Y prepared by the pulsed laser deposition (PLD) technique and outlines their advantages as well as their shortcomings.

\section{OUTLINE OF EXPERIMENTAL FACILITIES}

\section{A. PLD apparatus for the synthesis of thin film metallic photocathodes}

The PLD chamber used for the deposition of metallic thin films consists of a high vacuum system in which the substrate is placed parallel and in front of the metallic target as shown in Fig. 1.

The target is ablated by laser irradiation guided by an optical system comprising lenses and mirrors. The used laser source was an $\mathrm{UV} \mathrm{XeCl}$ excimer laser (LambdaPhysik, LPX 315i, $\lambda=308 \mathrm{~nm}, \tau=30 \mathrm{~ns}$, repetition rate of $10 \mathrm{~Hz}$ ). A new set of experiments is planned by a

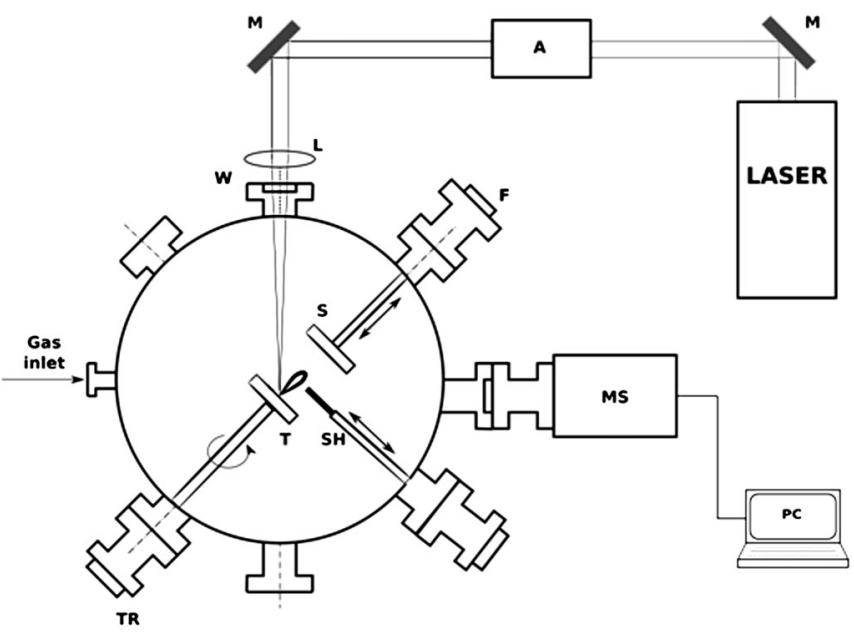

FIG. 1. Experimental setup. M: mirror; A: attenuator; L: lens; T: target; $\mathbf{S}$ : substrate; W: laser window; MS: mass spectrometer; F: $x-y$ substrate motion system; TR: target rotation feedthrough; SH: shutter.

$\mathrm{Nd}$ :YAG laser operating in third $(\lambda=355 \mathrm{~nm})$ and fourth $(\lambda=266 \mathrm{~nm})$ harmonics.

The laser spot size is adjusted by a movable focusing lens, while the laser energy density is controlled by a filter energy attenuator. The substrate is placed in front of the target at a distance of $5 \mathrm{~cm}$. For the film deposition, 30000 subsequent laser pulses were applied. Before each successive deposition event, the target surface was cleaned by applying 2000 laser pulses. During this time, a shutter was interposed between the target and the substrate to avoid the deposition of the ablated material from the first layers of the target, usually contaminated. Depositions are carefully carried out in order to obtain thin films as pure as possible. Rotary and turbomolecular oil-free pumps form the pumping system, which allow the evacuation of the vacuum chamber up to $10^{-6} \mathrm{~Pa}$.

A mass spectrometer (Hiden Analytical HALO 201 RC) allows us to control the quality of the vacuum before, during, and after the film deposition. It was observed that the final vacuum level after the deposition was slightly improved. The idea is that the metallic layer deposited on the internal wall of the vacuum system induces the getter effect reducing the partial pressure of reactive chemical species like $\mathrm{H}_{2} \mathrm{O}, \mathrm{H}_{2}$, and $\mathrm{O}_{2}$ molecules.

\section{B. Photodiode cell for QE testing}

The QE measurements are performed in a photodiode cell under UHV condition. The cathode and the anode, separated at a distance of $3 \mathrm{~mm}$, are placed inside the photodiode cell (Fig. 2). The sample occupies the cathode position and is electrically grounded. The anode plate is biased with high DC voltages up to $5 \mathrm{kV}$ thus allowing the generation inside the gap of an intense electric field of about $1.7 \mathrm{MV} / \mathrm{m}$. 


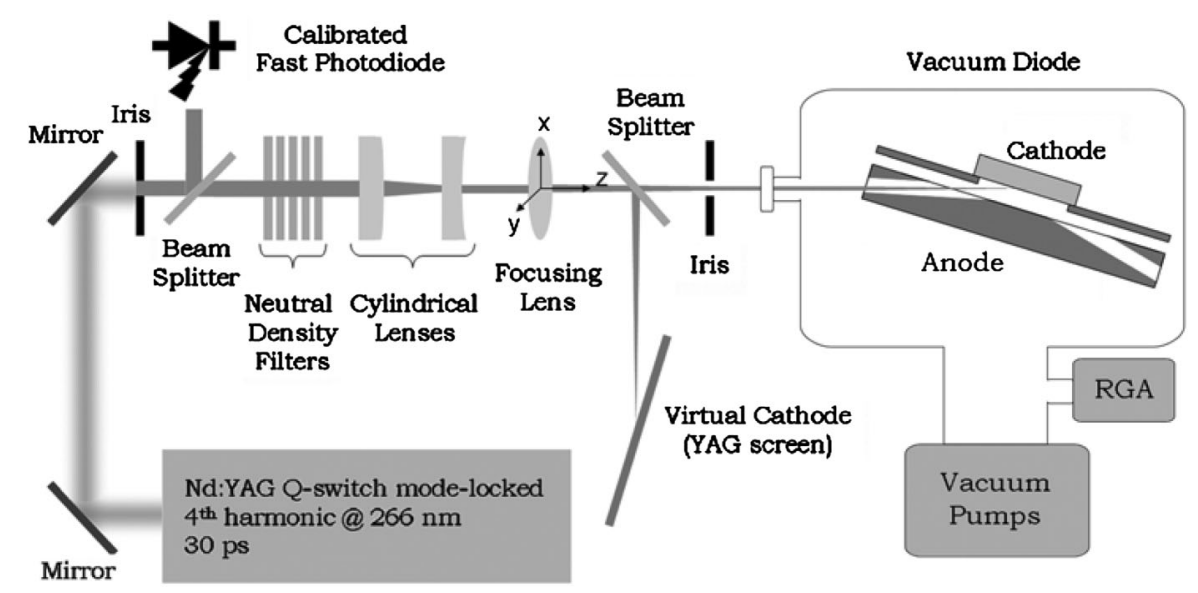

FIG. 2. Experimental setup for photocathode testing.

In order to illuminate the cathode and for precise alignment of the UV laser beam on the cathode surface, the anode plate is machined with two symmetric holes. The vacuum chamber, in which the photodiode cell is inserted, is evacuated at a base pressure of about $2 \times 10^{-7} \mathrm{~Pa}$ by means of rotary-turbomolecular and ionic oil-free pumps.

A $Q$-switched and mode-locked Nd:YAG laser (QUANTEL YG-501) operating at 4th harmonic (266 nm) with pulse duration of $30 \mathrm{ps}$ is used to test the photoemission performance of metallic thin film based photocathodes and for the laser cleaning processes of the photocathode surface.

\section{EXPERIMENTAL RESULTS}

Several laser parametric studies have been performed in order to improve the quality of metallic thin films prepared by the PLD technique. The optimal laser parameters strongly depend on the material under investigation. In particular, the importance of laser fluence has been investigated to obtain good quality films in terms of morphological features and chemical purity. With metals, for example, the droplet density observed on the film surface decreases with the increasing of the laser fluence [25,26]. Moreover,

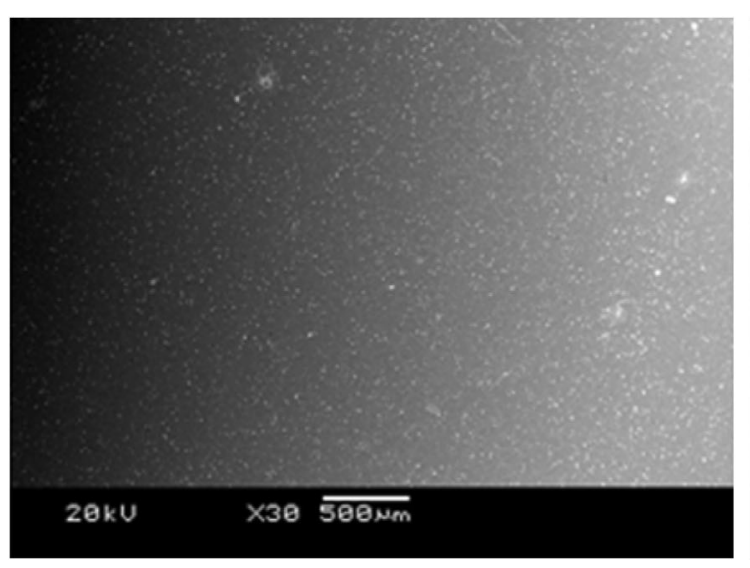

time-resolved mass spectrometric investigations during the laser ablation of $\mathrm{Mg}$ and $\mathrm{Y}$ showed that the partial pressure of $\mathrm{MgO}$ and $\mathrm{YO}$ increased with the laser fluence [27]. Therefore, a compromise between good quality films in terms of chemical and morphological properties and a reasonable deposition rate should be found out for each material.

Detailed studies were also carried out to deduce the influence of laser pulse duration on the thin film quality of $\mathrm{Mg}$ and $\mathrm{Y}$. Morphological analyses performed by scanning electron microscopy (SEM) revealed that the density and mean size of droplets on $\mathrm{Mg}$ film surfaces decreases as the pulse laser duration diminishes [28]. Therefore sub-ps lasers should be used for this metal even if the ablation and deposition rates are quite small. On the contrary, it was also found that the laser ablation, and thus deposition, of yttrium in the ns regime is by far more appropriate than $\mathrm{ps}$ and sub-ps regimes [29].

\section{A. Photocathodes based on Mg thin films}

Figure 3 shows the SEM micrographs of a Mg film surface deposited by a ns laser on a $\mathrm{Cu}$ substrate at two

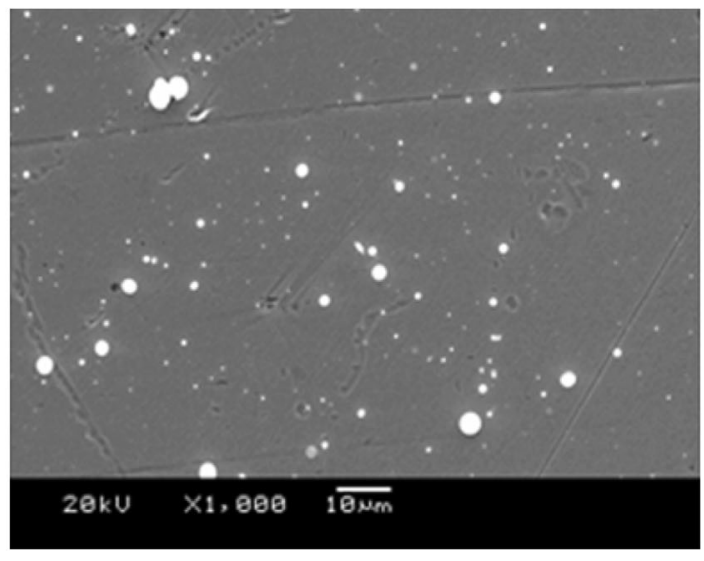

FIG. 3. SEM images of $\mathrm{Mg}$ thin film deposited on $\mathrm{Cu}$ at two different magnifications. Length of scale markers is indicated in the images. 


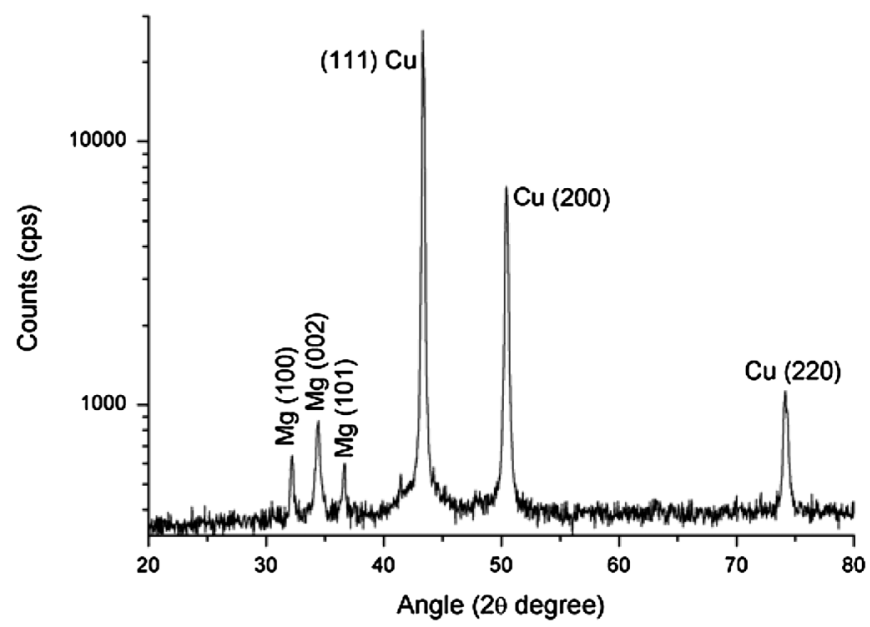

FIG. 4. The x-ray diffraction technique (XRD) spectrum of the $\mathrm{Mg}$ thin film deposited on $\mathrm{Cu}$ substrate.

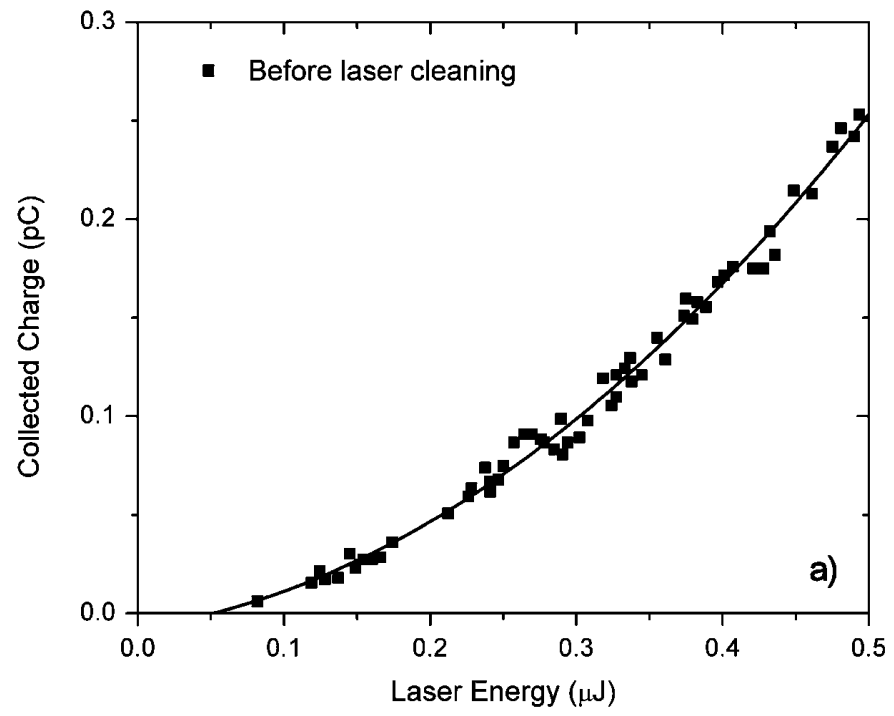

different magnifications. The droplets on the film surface have a spherical shape with a diameter of a few $\mu \mathrm{m}$. The droplet formation is due to many processes arising during the laser-target and laser-plasma interactions, which could be responsible of liquid-phase expulsion, as well as of hydrodynamic instabilities.

$\mathrm{Mg}$ thin films were found to be polycrystalline with $\mathrm{Mg}$ (100), Mg (002), and Mg (101) peaks shown in Fig. 4. The crystallinity of the films is attributed to the effect of energetic species present in the plume, which promote the surface atom mobility. Time of flight measurements demonstrated, indeed, that the ion mean kinetic energy of the plasma can reach some hundreds of eV depending on laser fluence [30,31].

The photoemission performances of $\mathrm{Mg}$ photocathodes have been studied by the $266 \mathrm{~nm}$ laser wavelength. The formation of oxidation layers on the surface of the cathode

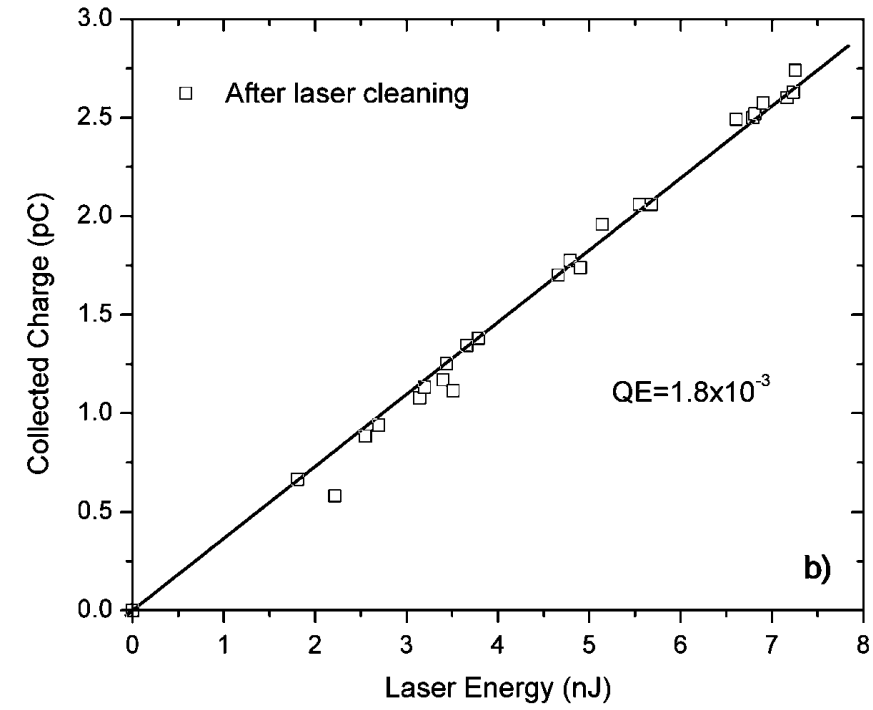

FIG. 5. Collected charge as a function of laser energy before (a) and after (b) in situ laser cleaning treatment. Continuous lines are the data-fitting curves.
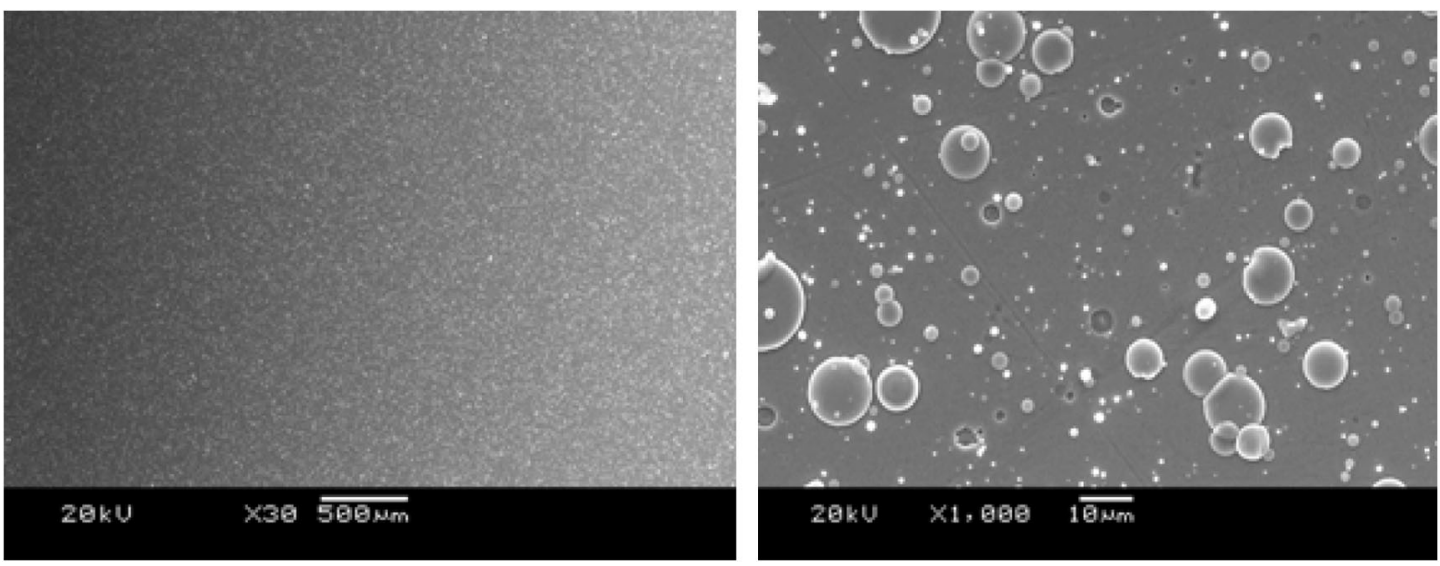

FIG. 6. SEM images of $\mathrm{Y}$ thin film deposited on $\mathrm{Cu}$ at two different magnifications. Length of scale markers is indicated in the images. 
TABLE I. Physical properties of various metallic photocathodes.

\begin{tabular}{|c|c|c|c|c|}
\hline & $\mathrm{Cu}$ & $\mathrm{Mg}$ & $\mathrm{Y}$ & $\mathrm{Pb}$ \\
\hline Work function & $4.5 \mathrm{eV}$ & $3.7 \mathrm{eV}$ & $3.0 \mathrm{eV}$ & $4.0 \mathrm{eV}$ \\
\hline $\mathrm{QE}$ & $1.4 \times 10^{-4}$ at $266 \mathrm{~nm}$ & $6.2 \times 10^{-4}$ at $266 \mathrm{~nm}$ & $\begin{array}{l}5 \times 10^{-4} \text { at } 266 \mathrm{~nm} \\
1.1 \times 10^{-5} \text { at } 406 \mathrm{~nm}\end{array}$ & $1 \times 10^{-3}$ at $213 \mathrm{~nm}$ \\
\hline Thermal conductivity & $4.0 \mathrm{~W} /(\mathrm{cm} \mathrm{K})$ & $1.55 \mathrm{~W} /(\mathrm{cm} \mathrm{K})$ & $0.17 \mathrm{~W} /(\mathrm{cm} \mathrm{K})$ & $0.35 \mathrm{~W} /(\mathrm{cm} \mathrm{K})$ \\
\hline Thermal diffusivity & $116 \times 10^{-6} \mathrm{~m}^{2} / \mathrm{s}$ & $87.9 \times 10^{-6} \mathrm{~m}^{2} / \mathrm{s}$ & $13.5 \times 10^{-6} \mathrm{~m}^{2} / \mathrm{s}$ & $19.6 \times 10^{-6} \mathrm{~m}^{2} / \mathrm{s}$ \\
\hline Electrical resistivity & $1.72 \times 10^{-8} \Omega \mathrm{m}$ & $144 \times 10^{-8} \Omega \mathrm{m}$ & $59.6 \times 10^{-8} \Omega \mathrm{m}$ & $20.6 \times 10^{-8} \Omega \mathrm{m}$ \\
\hline Chemical reactivity & Low & Very High & High & Low \\
\hline $\begin{array}{l}\text { Suggested vacuum } \\
\text { level during deposition }\end{array}$ & $<10^{-4} \mathrm{~Pa}$ & $<10^{-6} \mathrm{~Pa}$ & $<10^{-5} \mathrm{~Pa}$ & $<10^{-4} \mathrm{~Pa}$ \\
\hline $\begin{array}{l}\text { Vacuum level during } \\
\text { QE testing }\end{array}$ & $<10^{-7} \mathrm{~Pa}$ & $<10^{-8} \mathrm{~Pa}$ & $<10^{-8} \mathrm{~Pa}$ & $<10^{-6} \mathrm{~Pa}$ \\
\hline
\end{tabular}

is responsible of a photoemission induced by a multiphoton absorption. According to the generalized Fowler-Dubridge theory [32,33], for high laser intensities, the electrons can be emitted even for the sub-work function energy photon by a multiphoton absorption process. The collected charge, $Q$, follows the law [34]:

$$
Q=K I^{n} \tau A
$$

where $K$ is a constant, $I$ is the laser power density, $\tau$ is the laser pulse length, and $A=\left(\pi \sigma_{t}^{2}\right) / 4$ is transverse area of the laser beam. The power law presented in Eq. (3) takes into account the photoemission induced by $n$-photon absorption.

As Fig. 5(a) shows, the quadratic slope of the collectedcharge data as a function of the laser energy is the evidence of a contribution of the photoemission mainly induced by the absorption of two photons.

After a dedicated laser cleaning of the surface, the photoemission is mainly induced by single photon absorption as the linear trend of the data of Fig. 5(b) shows. In this case the QE can be computed as the number of emitted

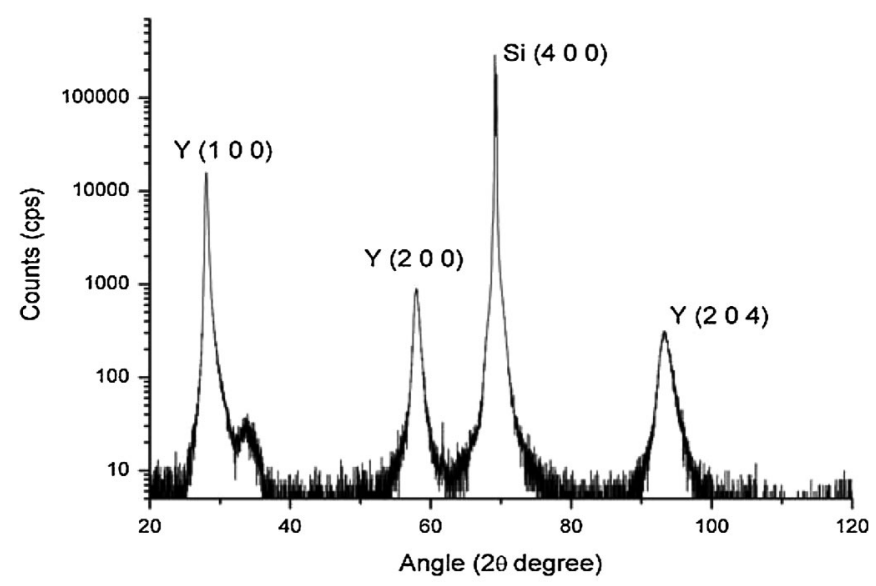

FIG. 7. XRD spectrum of the Y thin film deposited on Si (100) substrate. electrons on the number of incident photons, resulting to be about $1.8 \times 10^{-3}$.

\section{B. Photocathodes based on Y thin films}

SEM micrographs of the $Y$ thin film are shown in Fig. 6 at two different magnifications. The film surface is richer of droplets than the $\mathrm{Mg}$ film, probably due to the lower thermal diffusivity of $\mathrm{Y}$ (see Table I). This fact could increase the melting layer thickness as well as the droplet size and the droplet density on the film surface.

In this case, we have also obtained polycrystalline Y films. In Fig. 7, an example of XRD spectrum of Y film deposited on $\mathrm{Si}$ (100) substrate is shown. The strong XRD peaks at around $28.0^{\circ}, 58.0^{\circ}$, and $93.3^{\circ}$ in the $2 \Theta$ angle are associated to the (100), (200), and (204) polycrystalline planes of $\mathrm{Y}$, respectively. The weak signal at around $33^{\circ}$ could be attributed to either the formation of a thin thickness of yttrium oxide due to the air exposure or the $\mathrm{Si}$ (200) from the substrate.

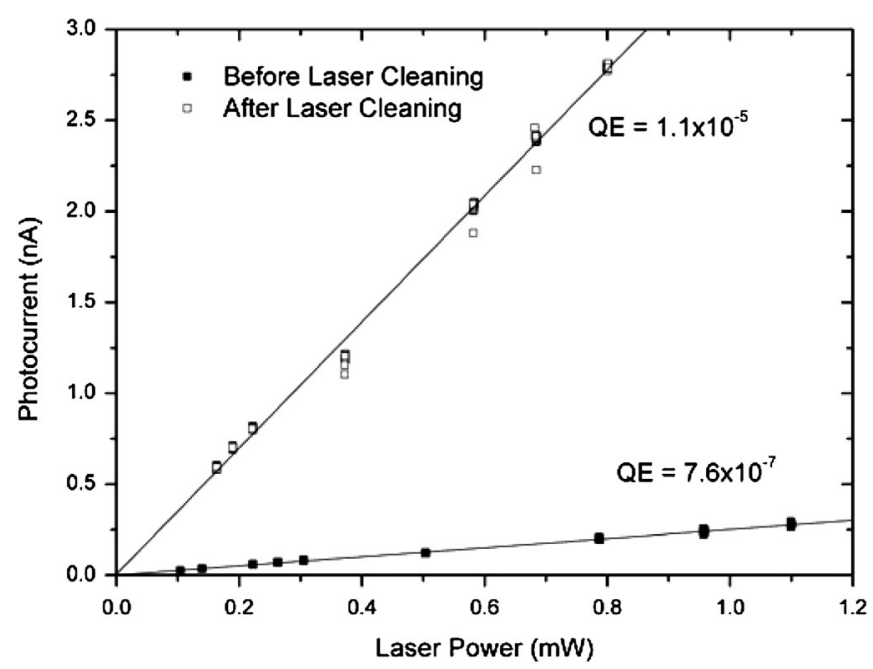

FIG. 8. Photocurrent as a function of laser power before and after in situ laser cleaning treatment (data points). The continuous line is the linear fitting curve to derive the $\mathrm{QE}$ value. 
A $\mathrm{cw}$ laser diode at $406 \mathrm{~nm}$ was used to study the photoemission performance of $Y$ cathodes. Figure 8 shows the obtained photoemitted current as a function of the laser power.

Before the laser cleaning, the relatively low laser power rules out the contribution of the multiphoton absorption photoemission showing very weak values of the photocurrent. The linear trend shown in the above figure confirms the exclusive presence of single photon process with a resulting $\mathrm{QE}$ of $7.6 \times 10^{-7}$. After the laser cleaning treatment, the QE increases up to a value of $1.1 \times 10^{-5}$ due to the removing of the contaminated layers from the photocathode surface.

\section{CONCLUSION}

This work summarizes the main results obtained by the PLD technique to realize photocathodes based on $\mathrm{Mg}$ and $\mathrm{Y}$ thin films. Mg based photocathodes are characterized by a high QE, which has been found to be of about $10^{-3}$ at $266 \mathrm{~nm}$. Y based photocathodes are also interesting due to its low work function $(\sim 3.0 \mathrm{eV})$. This fact makes possible to drive such cathodes by visible wavelength improving the brightness of electron beams in rf guns.

The optimization of the laser parameters during the deposition of metallic films is a very important challenge in order to obtain good quality films in terms of morphological features and chemical quality. The high kinetic energy of the ablated material improves the adherence of the film on the substrate as well as the formation of crystalline structures. This result could be interesting in the research and development field of photocathodes because the formation of crystalline structures on the deposited films could improve the photoemission performance of photocathodes [35].

The formation of contaminant layers on the film surface, due to the air exposure and residual gas in the vacuum chamber, decreases the QE of the photocathode. For this reason, in situ laser cleaning processes are mandatory in order to improve the photoemission performances of such metallic photocathodes. With the aim of obtaining relatively high QE with a longer lifetime, photocathodes based on $\mathrm{Pb}$ thin films will be investigated taking special care of reducing the contamination processes. This metal is a promising candidate to be used in hybrid lead-niobium superconducting rf cavities.

\section{ACKNOWLEDGMENTS}

This work was supported by the Italian National Institute of Nuclear Physics (INFN).

[1] J. B. Rosenzweig et al., Nucl. Instrum. Methods Phys. Res., Sect. A 593, 39 (2008).
[2] A. Cianchi et al., Phys. Rev. ST Accel. Beams 11, 032801 (2008).

[3] D. Alesini et al., Laser Part. Beams 22, 341 (2004).

[4] D. Alesini et al., Nucl. Instrum. Methods Phys. Res., Sect. A 507, 345 (2003).

[5] J. R. Maldonado, Z. Liu, D. H. Dowell, R. E. Kirby, Y. Sun, P. Pianetta, and F. Pease, Phys. Rev. ST Accel. Beams 11, 060702 (2008).

[6] C.P. Hauri, R. Ganter, F. Le Pimpec, A. Trisorio, C. Ruchert, and H. H. Braun, Phys. Rev. Lett. 104, 234802 (2010).

[7] T. Srinivasan-Rao, J. Schill, I. Ben Zvi, and M. Woodle, Rev. Sci. Instrum. 69, 2292 (1998).

[8] J. Smedley, T. Rao, and J. Sekutowicz, Phys. Rev. ST Accel. Beams 11, 013502 (2008).

[9] H. J. Qian, J. B. Murphy, Y. Shen, C. X. Tang, and X. J. Wang, Appl. Phys. Lett. 97, 253504 (2010).

[10] V. G. Tkachenko, A. I. Kondrashev, and I. N. Maksimchuk, Appl. Phys. B 98, 839 (2010).

[11] W.E. Spicer, Phys. Rev. 112, 114 (1958).

[12] C. N. Berglund and W. E. Spicer, Phys. Rev. 136, A1030 (1964).

[13] D. H. Dowell and J.F. Schmerge, Phys. Rev. ST Accel. Beams 12, 074201 (2009).

[14] T. Srinivasan-Rao, J. Fisher, and T. Sang, J. Appl. Phys. 69, 3291 (1991).

[15] L. Cultrera, C. Ristoscu, G. Gatti, P. Miglietta, F. Tazzioli, and A. Perrone, J. Phys. D 40, 5965 (2007).

[16] L. Cultrera, S. Grigorescu, G. Gatti, P. Miglietta, F. Tazzioli, and A. Perrone, J. Nanosci. Nanotechnol. 9, 1585 (2009).

[17] J. P. Girardeau-Montaut, M. Afif, C. Tomas, A. F. Obaton, C. Girardeau-Montaut, and K. Warda, Appl. Surf. Sci. 106, 451 (1996).

[18] X. J. Wang, M. Babzien, X. Y. Chang, D. Lynch, $\mathrm{S}$. Pjerov, M. Woodle, and $\mathrm{Z}$. Wu, in Proceedings of the 8th European Particle Accelerator Conference, Paris, 2002 (EPS-IGA and CERN, Geneva, 2002), p. 1822.

[19] Q. Yuan, A. W. Baum, R. F. W. Pease, and P. Pianetta, J. Vac. Sci. Technol. B 21, 2830 (2003).

[20] T. Nakajyo, J. Yang, F. Sakai, and Y. Aoki, Jpn. J. Appl. Phys. 42, 1470 (2003).

[21] X. J. Wang, T. Srinivasan-Rao, K. Batchelor, I. Ben-Zvi, and J. Fischer, Nucl. Instrum. Methods Phys. Res., Sect. A 356, 159 (1995).

[22] L. Cultrera, G. Gatti, P. Miglietta, F. Tazzioli, and A. Perrone, Nucl. Instrum. Methods Phys. Res., Sect. A 587, 7 (2008).

[23] L. Cultrera, G. Gatti, and A. Lorusso, Radiat. Eff. Defects Solids 165, 609 (2010).

[24] J. Smedley, T. Rao, and J. Sekutowicz, Phys. Rev. ST Accel. Beams 11, 013502 (2008).

[25] A. Lorusso, V. Fasano, K. Lovchinov, and A. Perrone, J. Vac. Sci. Technol. A 29, 031502 (2011).

[26] E. Van de Riet, C. J.C. M. Nillesen, and J. Dieleman, J. Appl. Phys. 74, 2008 (1993).

[27] F. Gontad, A. Lorusso, and A. Perrone (unpublished).

[28] P. Miglietta, L. Cultrera, C. Cojanu, E. L. Papadopoulou, and A. Perrone, Appl. Surf. Sci. 255, 5228 (2009). 
[29] A. Lorusso, M. L. De Giorgi, V. Fasano, C. Fotakis, P. Miglietta, EL. Papadopoulou, and A. Perrone (unpublished).

[30] L. Torrisi and D. Margarone, Plasma Sources Sci. Technol. 15, 635 (2006).

[31] D. Doria, A. Lorusso, F. Belloni, V. Nassisi, L. Torrisi, and S. Gammino, Laser Part. Beams 22, 461 (2004).
[32] R. H. Fowler, Phys. Rev. 38, 45 (1931).

[33] L. A. Dubridge, Phys. Rev. 43, 727 (1933).

[34] G. Ferrini, F. Banfi, C. Giannetti, and F. Parmigiani, Nucl. Instrum. Methods Phys. Res., Sect. A 601, 123 (2009).

[35] E. Pedersoli et al., Appl. Phys. Lett. 93, 183505 (2008). 